\title{
CORRECTION
}

View Article Online

View Journal I View Issue

W) Check for updates

Cite this: RSC Adv., 2021, 11, 34424

\section{Correction: Simultaneous quantification of five biomarkers in ethanolic extract of Cassia occidentalis Linn. stem using liquid chromatography tandem mass spectrometry: application to its pharmacokinetic studies}

\author{
Mohammed Riyazuddin, $\uparrow^{\mathrm{a}}$ Athar Husain, $\dagger^{\text {ad }}$ Saurabh Verma, ${ }^{\text {ad }}$ Roshan Katekar, ${ }^{\text {ad }}$ \\ Richa Garg, ${ }^{\text {ad }}$ Sudhir Kumar, ${ }^{\mathrm{b}}$ Sabbu Satish, ${ }^{\mathrm{b}}$ Rakesh Maurya, ${ }^{\mathrm{b}}$ Tadigoppula Narender, \\ Naibedya Chattopadhyay ${ }^{c}$ and Jiaur R. Gayen ${ }^{\star a d}$ \\ Correction for 'Simultaneous quantification of five biomarkers in ethanolic extract of Cassia occidentalis \\ Linn. stem using liquid chromatography tandem mass spectrometry: application to its pharmacokinetic \\ studies' by Mohammed Riyazuddin et al., RSC Adv., 2020, 10, 4579-4588. DOI: 10.1039/C9RA07482A
}

DOI: 10.1039/d1ra90162a

rsc.li/rsc-advances

The authors regret that the one of the affiliations (affiliation d) was incorrectly shown in the original manuscript. The corrected list of affiliations is as shown above.

The Royal Society of Chemistry apologises for these errors and any consequent inconvenience to authors and readers.

aPharmaceutics \& Pharmacokinetics Division, CSIR-Central Drug Research Institute, Sector-10, Jankipuram Extension, Sitapur Road, Lucknow-226031, India. E-mail: jr.gayen@ cdri.res.in; Tel: +912772450 ext. 4845

${ }^{b}$ Medicinal \& Process Chemistry Division, CSIR-Central Drug Research Institute, Lucknow-226031, India

${ }^{c}$ Endocrinology Division, CSIR-Central Drug Research Institute, Lucknow-226031, India

${ }^{d}$ Academy of Scientific and Innovative Research (AcSIR), Ghaziabad 201002, India

$\dagger$ These authors contributed equally. 